\title{
Infectious arthritis caused by Propionibacterium acnes: a report of two cases
}

\author{
M F KOOIJMANS-COUTINHO, H M MARKUSSE, AND B A C DIJKMANS
}

From the Department of Rheumatology, University Hospital, Leiden, The Netherlands

SUMMARY Propionibacterium acnes, a micro-organism with low pathogenicity, rarely causes arthritis in a joint without a prosthesis. This report deals with two cases of $P$ acnes infectious arthritis probably caused by direct penetration of the micro-organism into the joint space during arthrocentesis, despite the use of strict disinfection procedures. $P$ acnes isolated from synovial fluid cannot be dismissed as a bothersome contaminant without due consideration of the clinical status of the individual patient.

Infectious arthritis is generally thought to be caused by haematogenous spread of bacteria, ${ }^{1}$ and the most common causative micro-organisms are Staphylococcus aureus, $S$ epidermidis, streptococci, and Gram negative rods. ${ }^{12}$ Infectious arthritis caused by the skin commensal Propionibacterium acnes is extremely rare in joints in which no prosthetic material is present. ${ }^{3}$

This report concerns two patients with arthritis caused by $P$ acnes, which was probably introduced during injection or aspiration.

\section{Case reports}

\section{CASE 1}

A 52 year old woman had suffered since 1982 from seronegative rheumatoid arthritis, for which she had been treated with non-steroidal anti-inflammatory drugs. In June 1986 triamcinolone acetonide $20 \mathrm{mg}$ was injected into the left knee because of active synovitis. Three days later the joint showed erythema, warmth, and abundant effusion. Aspiration of the knee yielded cloudy fluid with a white cell count of $10.8 \times 10^{9}$ cells $/ \mathrm{l}$, polymorphonuclear leucocytes accounting for $76 \%$. Gram staining showed 0-1 Gram positive rods per field. In cultures of this aspirate and one collected two days later $P$ acnes appeared after four days of incubation. No

Accepted for publication 13 February 1989.

Correspondence to $\mathrm{Dr}$ M F Kooijmans-Coutinho, University Hospital, Department of Rheumatology, Building 1, C2-Q, PO Box 9600,2300 RC Leiden, The Netherlands. bacteria were seen in the Gram preparation of the second aspirate.

On admission the patient appeared to be in good health. Her body temperature was $37 \cdot 8^{\circ} \mathrm{C}$. Physical examination was unremarkable, except for signs of arthritis in the left knee. None of the other joints showed signs of active synovitis. The sedimentation rate was $60 \mathrm{~mm}$ in the first hour (Westergren), haemoglobin concentration was $119 \mathrm{~g} / \mathrm{l}$, and the white blood cell count was $8.7 \times 10^{9} / 1$, including $76 \%$ polymorphonuclear leucocytes. Normal values or negative results were obtained for liver enzymes, serum glucose, serum creatinine, the Rose-Waaler test, the latex fixation test, and antinuclear antibodies. Radiography of the knee showed no evidence of bone erosion or joint space narrowing.

The diagnosis was infectious arthritis of the left knee caused by $P$ acnes. Penicillin was given intravenously, $2 \times 10^{6}$ units six times daily. After four weeks all signs of inflammation had disappeared, and oral feneticillinepotassium 1250 $\mathrm{mg}$ was given twice daily for another two weeks. Repeated aspiration of synovial fluid over a three week period showed that the declining white blood cell count reached $4.0 \times 10^{9} / 1$. The patient remained asymptomatic after the treatment was stopped.

CASE 2

A 28 year old woman had suffered since 1977 from a seronegative rheumatoid arthritis, for which she had been treated with non-steroidal anti-inflammatory drugs and antimalarial drugs. Since 1983 she had 
been receiving parenteral gold treatment. In December 1987 she developed active synovitis of the right knee, and in March 1988 arthrocentesis of this joint was carried out twice without introduction of corticosteroid drug treatment. Cultures of synovial fluid showed no micro-organisms on either occasion. After the second puncture progressive pain, swelling, warmth, and redness of the joint were noted. Repeat arthrocentesis on two consecutive days showed no micro-organisms in the Gram stained preparations, but after six days cultures of both specimens showed $P$ acnes. The white blood cell count in the synovial fluid was $8.4 \times 10^{9} / 1(69 \%$ polymorphonuclear leucocytes) and $5.3 \times 10^{9} / 1 \quad(59 \%$ polymorphonuclear leucocytes) in the first and second fluid samples respectively.

At admission we saw a young woman apparently in good health. Her body temperature was $36 \cdot 4^{\circ} \mathrm{C}$. Physical examination was unremarkable, except for arthritis of the right knee joint. No other joints showed signs of active synovitis. The sedimentation rate was $53 \mathrm{~mm}$ in the first hour (Westergren), the haemoglobin concentration was $111 \mathrm{~g} / \mathrm{l}$, and the white blood cell count was $6 \cdot 5 \times 10^{9} / 1$ with normal differentiation. Normal values or negative results were obtained for liver enzymes, serum glucose, serum creatinine, the Rose-Waaler test, the latex fixation test, and antinuclear antibodies.

An $x$ ray examination of the knees showed no sign of destruction. The diagnosis was infectious arthritis of the right knee caused by $P$ acnes. Because of a known penicillin hypersensitivity the patient was given clindamycin phosphate intravenously, $600 \mathrm{mg}$ four times daily. Repeated aspiration of synovial fluid showed a decrease of the white blood cell count, which reached $1.2 \times 10^{9} / 1$ after two weeks' treatment. At that time all signs of inflammation had disappeared, and oral clindamycin ( $300 \mathrm{mg}$ four times daily) was given for another four weeks. Subsequently, the patient remained asymptomatic.

\section{Discussion}

$P$ acnes is a Gram positive bacillus that is usually strictly anaerobic, but some micro-aerophilic strains are known. ${ }^{4}$ This micro-organism is found on normal skin ${ }^{4}$ and has limited intrinsic pathogenicity. $P$ acnes has rarely been reported to cause infectious arthritis except in the presence of a prosthesis. ${ }^{34}$ As far as we know, only two cases of $P$ acnes infection of a joint without a prosthesis have been reported, ${ }^{35}$ and reports on a large series of cases of infectious arthritis make no mention of arthriti caused by $P$ acnes. ${ }^{126}$

As $P$ acnes recovered from blood cultures is often considered to be a contaminant ${ }^{7-9}$ a positive culture should be assessed in the light of the clinical setting In both of our cases $P$ acnes was isolated from the synovial fluid twice and on two separate occasions which makes contamination of the sampl $\vec{\Phi}$ improbable. Bacterial arthritis is usually acquire haematogenously, but bacteria may also be directls? introduced into a joint by an intra-articula $\bar{p}$ injection. ${ }^{1}$

Possibly in our patients contamination with acnes was followed by a secondary infection ines curred during the aspiration of synovial fluid. Inade? quacy of the disinfection procedure cannot com $\stackrel{\overrightarrow{P O}}{\mathrm{P}}$ pletely be ruled out, and it must be remembered that $P$ acnes is not easily accessible to disinfectiveo agents because it resides in the sebum produced by the numerous sebaceous glands emptying into the hair follicles in the skin. ${ }^{10}$ It may be assumed that contamination with $P$ acnes often occurs during intra-articular injections but rarely leads to infectio ${ }^{6}$ owing to the low pathogenicity of this bacterium

In conclusion, the weakly pathogenic $P$ acnes can cause arthritis in a joint without a prosthesis, \&nf the clinician should be aware that persistent syne

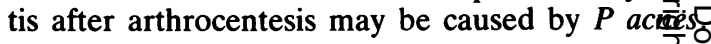

\section{References}

1 Meijers K A E, Dijkmans B A C, Hermans J, van den Broeñ $P$ J, Cats A. Non gonococcal infectious arthritis: a retrospectis study. J Infect 1987; 14: 13-20.

2 Goldenberg D L, Cohen A S. Acute infectious arthritis. Am $\bar{g}$ Med 1976; 60: 369-77.

3 Yocum R C, McArthur J, Petty B G, Diehl A M, Moench T R Septic arthritis caused by Propionibacterium acnes. JAM 1982; 248: 1740-1.

4 Gorbach S L. Other anaerobic bacteria. In: Mandell G L, et di eds. Principles and practice of infectious diseases. Chichester? Wiley, 1978: 1893-9.

5 Savolainen $H$, von Essen $R$, Nissinen A J, Jahkola Propionibacterium acnes in purulent arthritis: probable cause iatrogenic infection. $J$ Rheumatol 1988; 15: 1040-1.

6 Rosenthal J, Bole G, Robinson W D. Acute non-gonococca infectious arthritis. Arthritis Rheum 1980; 23: 889-97.

7 Morrey B F, Fitzgerald R H, Kelly P J, Dobyns J H, Washingtom J A. Diphtheroid osteomyelitis. J Bone Joint Surg [Am] $197 \underline{\underline{Z}}$ 59: $527-30$.

8 Wilson W R, Martin W J, Widkowske C J. AnaerobAs bacteriemia. Mayo Clin Proc 1972; 47: 639-46.

9 Bartholomew L E, Nelson F R. Corynebacterium acnes rheumatoid arthritis. Isolation and antibody studies. Anges Rheum Dis 1972; 31: 22-7.

10 Linzenmeier G. Serologie anaerober Corynebakterien. Ze tralblatt für Bakteriologie, Parasitenkunde, Infektionskran heiten und Hygiene 1957; 170: 85-90. 